Article

\title{
Improving the Tourist's Perception of the Tourist Destinations Image: An Analysis of Chinese Kung Fu Film and Television
}

\author{
Huan Chen ${ }^{1,+}$, Yifan Zuo ${ }^{1,+}$, Rob Law $^{2}$ (D) and Mu Zhang ${ }^{1, *(D)}$ \\ 1 Shenzhen Tourism College, Jinan University, Shenzhen 518053, China; V_chenhuan@163.com (H.C.); \\ zuoyifan2018@163.com (Y.Z.) \\ 2 School of Hotel and Tourism Management, The Hong Kong Polytechnic University, Hong Kong, China; \\ rob.law@polyu.edu.hk \\ * Correspondence: zhangmu@jnu.edu.cn; Tel.: +86-755-2693-1865 \\ + These authors contribute equally to this article.
}

check for

updates

Citation: Chen, H.; Zuo, Y.; Law, R.; Zhang, M. Improving the Tourist's Perception of the Tourist Destinations Image: An Analysis of Chinese Kung Fu Film and Television. Sustainability 2021, 13, 3875. https://doi.org/ $10.3390 /$ su13073875

Academic Editors: Wojciech

J. Cynarski, Thomas A. Green and John A. Johnson

Received: 17 March 2021

Accepted: 29 March 2021

Published: 1 April 2021

Publisher's Note: MDPI stays neutral with regard to jurisdictional claims in published maps and institutional affiliations.

Copyright: (C) 2021 by the authors. Licensee MDPI, Basel, Switzerland. This article is an open access article distributed under the terms and conditions of the Creative Commons Attribution (CC BY) license (https:/ / creativecommons.org/licenses/by/ $4.0 /)$.

\begin{abstract}
Cultural media, film, and television works can increase the popularity of the image of tourist destinations, thereby promoting the sustainable development of the tourism industry and obtaining economic benefits. This study takes Chinese kung fu film and television as examples to explore the mechanism of audience participation in the perception of tourist destinations. It further explores the mediating effect of cultural contact. The study took the image perception of tourist destinations as the dependent variable and audience participation as the independent variable. A total of 331 subjects were surveyed, and a multi-layer regression model was established to test the rationality and validity of the hypothetical theoretical model. The research results show that audience participation in martial arts films and television tourism can directly and indirectly affect the audience's perception of martial arts culture. At the same time, the viewer can achieve contact with martial arts culture through film and television, accordingly forming his or her perception of the destination. In other words, film and television audience participation can bring more cultural contact to the audience. In turn, cultural contact can enhance the image perception of tourist destinations and play an important intermediary role in the process of audience participation by enhancing the perception of tourist destinations. By confirming the variable relationship in Wushu film and television tourism, this research fills the gap between the two aspects, which contributes to promoting the two-way interaction between Wushu film and television works and tourism marketing and achieving the long-term sustainable development of tourism destinations.
\end{abstract}

Keywords: Chinese Kungfu film and television works; audience participation; cultural contact; image perception of tourist destinations; sustainable development

\section{Introduction}

In 2019, 14 ministries and commissions, including the State Administration of Sports, studied and formulated the Wushu Industry Development Plan (from 2019 to 2025), or "The Plan" for short. It states that the martial arts industry should be guided by Xi Jinping's thought of socialism with Chinese characteristics in the new era to promote positive interaction between martial arts and related industries. Additionally, The Plan inspires the integration and development of industries to carry forward the traditional Chinese martial arts culture. It also encourages the growth of the martial arts films and television industry and martial arts tourism to improve the martial arts industry chain constantly. Martial arts culture can be promoted with the help of film and television media to arouse the curiosity of more tourists, which can allow a growing number of people to come into contact with martial arts culture. In this context, though the analysis on the research methodology in martial arts tourism or detailed typology has rarely been made [1], we find significance in researching Chinese martial arts culture and film and television tourism. The material form of the cultural heritage of martial arts is not the motivation for 
tourism [2]. Therefore, martial arts culture must be appropriately conveyed to tourists to change tourists' perceptions emotionally.

As one of the forms of cultural tourism, film and television tourism has become an increasing phenomenon worldwide under the impetus of the development of entertainment and global tourism [3]. Film and television tourism can be described as a purposeful visit by tourists to destinations depicted in movies and TV shows, including tours around film production factories and related theme parks [4]. Film and television tourism has been considered the driving force for the development of most tourist destinations, and its importance as a marketing tool for tourist destinations is increasing day by day [5]. According to the survey and research conducted by Wen, viewers are mostly motivated to travel to the country shown in a movie or TV series because they want to learn more about the country's diet or fashion, that is, the lifestyle described in the movie [4]. In addition, film tourism can inspire one-third of casual tourists [6]. When the participation of tourists through watching TV shows is more emotional, visitors are more likely to visit film and television tourism locations [7].

The image perception of a tourist destination refers to the voluntary, multi-sensory, mainly pictorial, qualitative, conscious, and quasi-perceptual psychological experience of the destination. This experience overlaps or parallels other psychological experiences of tourists, including their feelings, perceptions, mental representations, cognitive maps, destination consciousness, memory, and attitudes [8]. As an important part of the construction of destination culture, tourist destination image depends on the in-depth interpretation, symbolization, and carrying degree of destination culture [9]. Film and television works can spread a large amount of information to the audience's mind, thereby stimulating the audience's perception of the image of tourist destinations [10]. The mechanism of how film and television enhance the image perception of local tourist destinations is still unclear [11]. According to previous research experience, the degree of audience participation in films is often regarded as one of the key factors affecting the development of film and television tourism [7]. This research will deeply explore the relationship between film and television and the image perception of tourist destinations. The authors of this research hope to promote the dissemination of film and television works further, meet the needs of local tourism economic growth, and encourage the development of film and television industrialization.

Audience participation is considered an important component of media use and effects, and it is a feature of active audiences who actively seek and experience media to achieve certain expectations and needs in media and communication [7]. With the deep participation of the audience, movie-watching can be transformed into an unforgettable and pleasant experience. The emotional participation of the audience through watching film and television works can help to enhance the image perception of the tourist destination of a filming location [12]. Film and television are disseminated as a culture through their respective departments and are shown publicly. Through this contact, the deep cultural atmosphere of the filming location gives the public a sense of belonging [4]. Therefore, cultural contact may play an important role in the relationship between audience participation and its image perception of tourist destinations.

In film and television tourism, the mechanism of how the audience participates in enhancing the image perception of tourist destinations is not yet fully clear. With the vigorous development of new media, scholars have focused on the media effects of film and television tourism to promote the development of tourist destinations effectively. Hao pointed out that young audiences and their destination perception involve complex information processing; in addition, mass media cannot easily reverse the prominent negative image [13]. At the theoretical level, audience participation affects tourists' behavioral intentions through the moderating effects of cognition and emotional image [14]. However, in the field of cultural tourism research, research flaws exist regarding the impact of changes in cultural contact on audience participation in enhancing the perception of the destination image. Most scholars study the sustainable development of the tourism industry from the environmental level, pointing out that the sustainable development in the tourism industry must be employed to protect the environment [15]. However, there are also analyses show 
that the field of sustainable tourism research is expanding and maturing, with greater emphasis on climate change, modeling, values, behavior, and theoretical progression the field [16]. Therefore, on the basis of existing research, this study explore the sustainable development of tourism from the perspective of film and television culture, and enriches the field of sustainable tourism research. The study confirms that film and television audience engagement enhance destination image perception, and that cultural contact plays an important mediating role between film and television audience engagement and destination image perception. It fills the research gap in Chinese martial arts films and television tourism. Through this research, we can clarify the driving force for the development of the tourism industry in the destination of film and television tourism and deepen the cultural practice of the interconnection between the film and television culture and the tourist destination. In doing so, the current research can help the industry meet the more diverse tourism needs of visitors and stimulate tourism consumption. Whether in terms of economic benefits, tourism motives, or cultural and social influences, film and television tourism will be an important part of the sustainable development of tourist destinations.

\section{Literature Review and Hypotheses}

\subsection{Literature Review}

Chinese martial arts is considered by many to symbolize the strength of the Chinese and their pride in their history. It has long been regarded as an important element of Chinese culture and national identity [17]. The excellent Chinese martial arts culture created by the millennium development of the Chinese is not only the permanent spiritual wealth of the Chinese, but also the foundation of the country's development process [18]. However, with rapidly development of Chinese economy, martial arts culture has slowly fade out of people's view. Now some people only focus on profit, but forget Chinese excellent traditional culture, this kind of thinking is quite detrimental to Chinese extensive and profound marginal culture [19].

Chinese martial arts is a good representative of Chinese traditional sports, which has always been discussed as a main point by martial arts experts and scholars because of its heritage in modem society. The circulating of Chinese martial arts is the specific channels and ways of martial arts heritage [20]. Mass media is an important complement to the traditional heritage way. TV, the Internet, books, and other mass media have a wide range of coverage and intuitive [18]. A successful filmic production with strong national features need to organically hybridize global-local culture in proper when it enters globally cultural competition. On one hand, it should have local cultural identity; on the other, it should also show a kind of universal cultural values accepted by other cultures [21]. Like any other culture, Chinese martial art is a dynamic cultural system evolving with progressive society toward diversification. It has a bright prospect in the future and may be widely used and of great significance [22].

Audience participation means that the audience actively seeks experience in media communication to meet certain expectations and needs [7]. Early research regarded audience participation as quasi-social interaction. Quasi-social interaction is considered the simplification of cognitive and emotional responses, interpersonal participation, and emotional bonds, and it is an important part of audience participation [23]. With the strengthening of media relations, the audience not only invests time costs through long-term attention but also emotional costs. Studies have found that audiences increase their participation by collecting information about the film and purchasing products related to the content of the film or actors. Audience members with high audience participation usually seek deeper interaction with the media, thus forming an emotional attachment to the film [24]. Kim's field survey of Korean audiences showed that emotional and behavioral participation are the driving factors that influence the film travel experience; however, cognitive participation does not affect the film travel experience [7]. Some scholars have applied reception theory to investigate the meaning of the audience's to a TV travel episode in "No Reservations" to explore the role of tourism in mediating cross-cultural relations [25]. The 
current research still has shortcomings in the study of the relationship between audience participation and cultural contact.

Tourists' perception of the destination image is affected by the overall impression of the destination and is related to the expected benefits and consumption value. The perception of the image of a tourist destination is a comprehensive impression formed by tourists' perceptions, emotions, viewpoints, and perspectives of the destinations [8,24]. In recent years, the formation and projection process of the image perception of tourist destinations has always been the main focus of the analyses on specific destinations. On the basis of a large amount of literature and the summary of the theoretical foundations of predecessors, some scholars have put forward the landmark "cogntive-emotional" model for tourist destination image, which divides the tourist's perceived image into cognitive and emotional images. Between them, the cognitive image refers to the tourist's understanding of the attributes of the tourist destination, while the emotional image pertains to the feeling of the tourist toward the destination. The two images have a direct impact on the composite image, and the cognitive evaluation will influence emotional evaluation to affect the overall image perception indirectly [26]. At present, most of the current research starts from the perspective of the tourist subject. In other words, existing works have examined the tourists' perceptions and views on tourist destinations and how this opinion affects tourists' behavioral intentions [27]. Studies have also shown that destination awareness and visit motivation have a direct impact on tourists' decision-making regarding their travel destination [28]. In-depth research on Chinese tourists have pointed out that the strong participation of Chinese consumers in movies and TV dramas has a significant impact on their international travel motivation. In terms of destination image, the ranking of the countries visited by Chinese tourists and the desire to visit when watching TV or TV dramas are consistent [4]. The role of the management organization of destination image is to take the movie as a functional component of destination image management by connecting the movie audience with the travel experience provided at the destination during the filming, shooting, and screening before the film is shown [6].

Cultural contact is a conceptual term for "the interest of the other party", which originates from ethnology, cultural studies, and anthropology. It refers to the situation where two cultures influence each other, which is related to the mutual borrowing and integration of cultural characteristics between different cultural systems, and its manifestation may be the one-way or two-way transmission of ideas, customs, material objects, etc. [29]. Film and television tourism grafts film and television plots with the tourism resources of the filming location. The rich local brand culture will also be injected into the film and television works. Visitors' own culture constitutes the interaction with the external environment. This cultural relationship not only refers to countries and ethnic groups but also pertains to the local culture and the culture visited [30]. Numerous scholars have conducted research on the authenticity of the experience in film and television tourism. Tourists themselves attribute the high value to their judgment of authenticity. Tourists' authenticity experience is often a complex result of personal history and knowledge, social processes, manifestations, and locations [31]. The formation of the audience's perception of the tourist destination image may be affected by the audience's cultural contact with the filming location. In the process of creating attractive destination images and attracting tourists to the destination, historical movies are limited by the audience's existing historical knowledge, and authenticity problems emerge for the movies and tour operators in the relevant destinations [32]. In a cross-cultural environment, similarity makes the audience more receptive to persuasion. Through constant contact with cultural symbols, increasing the audience's proximity to other cultures boosts the attractiveness of the destination [33], thereby promoting the development of destination tourism.

The image perception of a tourist destination is a concrete manifestation of the humanistic characteristics and soft power of a destination; meanwhile, the image perception of a tourist destination reflects the overall word-of-mouth and reputation of this form of tourism [34]. Current research has shown that the visitors' perception of a destination's 
image is largely based on images before and during their trip. Affected by the dissemination of film and television, the image of tourist destinations will be better "packaged" [35]. In previous studies, some scholars started from the basic principles of communication, such as communicators, audiences, media, content, and effects, and found that the shaping and dissemination of the image of tourist destinations is the key to the development of destination tourism. In this process, we need to consider the tastes and needs of the tourists as the audience [36]. From the perspective of marketing, some studies have regarded audiences as markets or consumers, segmented audiences according to the market, and produced programs or films with different characteristics according to various groups, thereby enhancing audience participation and shaping the positive tourism image of the tourist destination [37]. The above conclusion demonstrates that audience participation can enhance the image perception of tourist destinations. Previous research has not directly indicated that audience participation in film and television tourism affects the level of cultural contact. However, this effect has been proven in cultural tourism. Tourist participation can increase the degree of cultural contact in cultural tourism. Cultural contact has a positive impact on the unforgettable travel experience of tourists and fully mediates the relationship between tourist participation and an unforgettable travel experience [38]. However, research has shown that audience participation will directly or indirectly affect the audience's perception of the image of tourist destinations [14].

\subsection{Research Hypothesis}

The above-mentioned research focuses on examining the role of audience participation in the field of communication or marketing in the image perception of tourist destinations. However, it ignores the cultural contacts formed by film and television tourism as a new form of cultural tourism. In addition, the cultural contact phenomenon of martial arts films and television tourism is a more specific study. Martial arts culture is directly injected into film and television works so that it can interact and come into contact with the audience. China's martial arts industry has formed a diversified industrial structure system. However, only three categories meet industry standards, including the martial arts tourism industry based on historical and cultural resources, such as Shaolin Temple, Wudang, and Emei. The above three destinations all have corresponding film and television works for promotion. At the same time, these film and television works have a good reputation and deep participation from the audience. Nevertheless, the tourism effect of martial arts movies and the mechanism of the relationship between movies and destinations remain unclear.

On the basis of the above discussion, this research proposes the following hypotheses and models (as Figure 1):

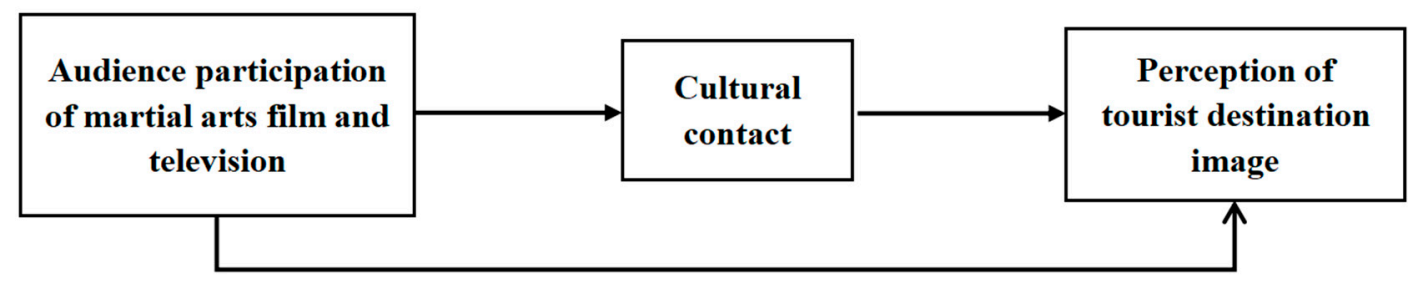

Figure 1. Conceptual model.

Hypothesis 1 (H1). A positive relationship exists between audience participation in martial arts films and television and the image perception of tourist destinations.

Hypothesis 2 (H2). A positive relationship exists between audience participation in martial arts films and television and cultural contact.

Hypothesis 3 (H3). A positive relationship exists between cultural contact and the image perception of tourist destinations. 
Hypothesis 4 (H4). Cultural contact has an intermediary effect between audience participation in martial arts films and television and the perception of tourist destination image.

\section{Research Method}

\subsection{Case Survey}

This article selected Foshan, China as a case study, which is famous for Chinese Kung Fu. Foshan, Guangdong (hereinafter referred to as Foshan) is located in the central part of Guangdong Province and the hinterland of the Pearl River Delta. It is one of the most economically developed regions in China. Moreover, it is in a leading position in the economic development of Guangdong Province, and the development of its tourism is also booming. The total number of overnight tourists in Foshan in 2019 was 19.33 million, which was more than a $14.01 \%$ growth from 2018. Tourism revenue reached 891.86 billion yuan in 2019, which was more than a $10.23 \%$ growth in 2018. The development of Foshan's tourism industry is expanding. As the main source of the China Southern School martial arts, Foshan was awarded the title "Martial Arts City" by the National Association of Martial Arts in 2014, thus becoming the only city officially dedicated to martial arts. In May 2020, the Foshan Municipal People's Government issued the Implementation Plan of Foshan City to Accelerate the Construction of the "World Kung Fu City," which proposed the development of the following objectives. By 2022, the city's martial arts population will reach 60 million with more than 10,000 martial arts practitioners. In addition, the city will build a kung fu center that integrates industry, performance, competition, research, and tourism and construct a complete ecological chain of kung fu cultural tourism.

Foshan tourism is deeply influenced by Chinese martial arts culture and martial arts films and television works. The "Huang Feihong" series, "Ip Man" series, "Bruce Lee" series, "Cai Lifo," and other film and television works have made Foshan famous all over the world. Furthermore, the city has almost become home to what used to be called the modern Chinese martial arts film. Foshan is the ancestral home of Huang Feihong, Ryazan, Ye Wen, and film and television martial arts star Bruce Lee. The Memorial Hall of Huang Feihong and Ye Wentang in the ancestral temple has become the most famous tourist attractions in the city [39]. Foshan's film and television works often involve a number of scenic resources, such as Xiqiao Mountain; Foshan Ancestral Temple; Qinghui Garden; and other cultural landscapes, historical landscapes, and subtropical rich natural landscapes.

At present, not much research has been conducted on the perception of Foshan's tourism image. Nevertheless, the following basic conclusions can be obtained. Foshan's overall tourism image perception among tourists depicts the area as a city with a very historical and cultural atmosphere and Lingnan cultural atmosphere, which is not much different from the image that people usually recognize. Tourist evaluations are positive, while tourism satisfaction is also high [40]. Foshan's traditional national sports tourism is the key to breaking the bottleneck of the development of Foshan's tourism industry. At present, the responsible entities must tap and sort out the resources of traditional national sports tourism. Through the historical accumulation of Foshan's traditional national sports, Foshan's own unique, scarce, and non-replicable tourism industry can be formed [41]. Film and television works related to Foshan martial arts focus on the Chinese martial arts celebrities that have emerged in Foshan's history, including Huang Feihong, Ip Wen, Bruce Lee, and Ryazan. Through artistic expression, the works perfectly interpret the lives of these individuals. Moreover, these productions have played a role in spreading Chinese martial arts culture to a large extent and promoted martial arts to be accepted and loved by a growing number of audiences. At the same time, these film and television works also spread and carry forward Foshan culture and Lingnan culture, thus allowing the culture of different regions to take part in communication and integration [39].

\subsection{Measurement Instrument}

This research explored the influence of audience participation and cultural contact on the image perception of tourist destinations in martial arts films and television tourism and 
whether cultural contact has an intermediary effect. Therefore, on the basis of previous experience, this study developed a scale survey process in accordance with standardized procedures [42]. As the survey was conducted in China, the scale was translated into Chinese [43] according to the reverse translation procedure. The content validity of the items in the scale for measuring each construct was evaluated by three scholars and two research assistants. They needed to provide an evaluation of the content and comprehensibility of the measurement items and then propose items that need to be re-edited and improved to enhance their clarity, readability, and content effectiveness. The expert group also needed to determine whether redundancy existed among the items and proposed improvements to the quota items for each construct.

\subsubsection{Audience Participation Scale}

This study adopted the Audience Participation Scale developed by Kim [7] and revised by Sood [44]. This scale is the most comprehensive tool for measuring audience participation. It comprehensively analyzes and conceptualizes previous research on audience participation. The scale has 15 questions divided into three dimensions, namely, behavioral participation, emotional participation, and referential mapping, using the five-level Likert scale to measure, with 1 pertaining to "strongly disagree" and 5 meaning strongly agree. In this study, the overall internal consistency coefficient of the scale was 0.925 . The internal consistency coefficients of the three dimensions of behavioral participation, emotional participation, and referential mapping were $0.835,0.859$, and 0.821 , respectively. In addition, the revised structural validity of the scale was good. The fitting index of confirmatory factor analysis was as follows: $\chi^{2} / d f=2.734$, RMSEA $=0.072, \mathrm{GFI}=0.910, \mathrm{NFI}=0.912, \mathrm{IFI}=0.943$, $\mathrm{TLI}=0.928$, and CFI $=0.942 . \chi^{2} / d f$ is the statistics of $\chi^{2}$ goodness-of-fit test. RMSEA: Root Mean Square Error of Approximation; GFI: Goodness of Fit index; NFI: Normative Fit Index; IFI is an amendment to NFI. TLI: Tucker-Lewis Index; CFI: Comparative Fit Index.

\subsubsection{Tourist Destination Image Perception Scale}

This study used tourist destination image perception scale developed by Baloglu and McCleary [26]. In the major scale to measure the subjects' perception of the tourism destination image of Foshan, a higher score increased the likelihood of the subjects to have a positive perception of Foshan's tourist destination image. The scale had 14 questions, which were divided into three dimensions: experience quality, tourist attractions, and value environment. The five-level Likert scale was used to measure, with 1 pertaining to "strongly disagree" and 5 representing "strongly agree." In this study, the overall internal consistency coefficient of the scale was 0.935, and the internal consistency coefficients of the three dimensions of experience quality, tourist attractions, and value nvironment were $0.899,0.840$, and 0.790 , respectively. The fitting index of the confirmatory factor analysis was as follows: $\chi^{2} / d f=2.846$, RMSEA $=0.075, \mathrm{GFI}=0.904, \mathrm{NFI}=0.924, \mathrm{IFI}=0.950$, $\mathrm{TLI}=0.937$, and CFI $=0.949$.

\subsubsection{Cultural Exposure Scale}

This study used the cultural contact scale developed by Gnoth and Zins [45]. The scale mainly tested the cognition of the subjects' exposure to martial arts culture in film and television works. A higher score entailed a strong likelihood for the subjects to recognize cultural contacts positively. The scale had a total of 11 questions and was measured by a five-level Likert scale, with 1 meaning "strongly disagree" and 5 denoting "strongly agree." In this study, the overall internal consistency coefficient of the scale was 0.924 . The fitting index of confirmatory factor analysis was as follows: $\chi^{2} / d f=2.763$, RMSEA $=0.073$, $\mathrm{GFI}=0.933, \mathrm{NFI}=0.941, \mathrm{IFI}=0.961, \mathrm{TLI}=0.952$, and $\mathrm{CFI}=0.961$.

\subsection{Data Collection}

Data collection took place from 30 May to 15 June 2020. This study adopted nonprobability sampling convenience sampling. It was distributed using the Internet and 
disseminated through social media platforms. The link for participants to fill out online is https://www.wjx.cn/mobile/index.aspx (accessed on 3 March 2021). Eventually, a total of 331 available sample data were collected. These samples came from 33 provinces, municipalities, and autonomous regions in China except Tibet, including a small number of samples from Ireland, Malaysia, Japan, and Singapore. As shown in Table 1,54.7\% of the respondents were men, and $45.3 \%$ were women. Most of the respondents were between 18-25 years old, or $56.8 \%$, and those under 35 years old accounted for $93.1 \%$. In addition, $95.5 \%$ of them graduated from high school, of which $86.7 \%$ had a bachelor's degree or above.

Table 1. Descriptive statistics of demographic characteristics $(\mathrm{N}=331)$.

\begin{tabular}{lll}
\hline Types & Quantity & $\%$ \\
\hline Gender & & \\
Male & 181 & 54.7 \\
Female & 150 & 45.3 \\
Age & 1 & \\
Under 18 years of age & 188 & 0.3 \\
$18-25$ & 119 & 56.8 \\
$26-35$ & 16 & 36.0 \\
$36-50$ & 6 & 4.8 \\
$51-60$ & 1 & 1.8 \\
Over 60 years old & 15 & 0.3 \\
Level of education & 29 & 4.5 \\
High school (secondary school) and below & 138 & 8.8 \\
Junior college & 149 & 41.7 \\
Undergraduate & & 45.0 \\
Postgraduate and above & & \\
\hline
\end{tabular}

\subsection{Data Analysis}

The data were analyzed using the Social Science Statistical Package (SPSS). First, we performed descriptive statistics on the demographic characteristics of the interviewees. Then, we used Cronbach's alpha to check the internal consistency of each construct. The results showed that the reliability was at an acceptable level. Then, we performed confirmatory factor analysis to check the aggregate validity of the questionnaire. Afterward, we calculated the descriptive statistics of each variable and related analysis results. To test the main effects of the model, a series of multiple regression analyses was first carried out. Finally, we used Bootstrap to test the mediation effect. In particular, Model 6 and Model 8 of the present study used a sample method of 5000 Bootstrap with a $95 \%$ confidence interval.

\section{Results}

\subsection{Demographic Profile}

Table 2 lists the mean, standard deviation, and correlation matrix of each main variable. The results showed that the correlation between all variables was significant. Among them, audience participation and tourism destination image perception were significantly positively correlated $(r=0.68, p<0.01)$, and audience participation and cultural contact were also significantly positively correlated $(\mathrm{r}=0.78, p<0.01)$. In addition, cultural contact was significantly positively correlated with the image perception of tourist destinations $(r=0.77, p<0.01)$. The average value of each variable was greater than 3.00 , thus indicating that the subjects as a whole had higher audience participation, cultural contact, and tourist destination perception of film and television. 
Table 2. Descriptive statistics and related analysis results of each study variable $(\mathrm{N}=331)$.

\begin{tabular}{|c|c|c|c|c|c|}
\hline & Average & $\begin{array}{l}\text { Standard } \\
\text { Deviation }\end{array}$ & $\begin{array}{c}\text { Audience } \\
\text { Participation }\end{array}$ & Cultural Contact & $\begin{array}{c}\text { Image Perception } \\
\text { of Tourist } \\
\text { Destinations }\end{array}$ \\
\hline Audience participation & 3.78 & 0.64 & 1 & & \\
\hline Cultural contact & 3.85 & 0.64 & $0.78 * *$ & 1 & \\
\hline $\begin{array}{l}\text { Image perception of } \\
\text { tourist destinations }\end{array}$ & 4.00 & 0.56 & $0.68^{* *}$ & $0.77^{* *}$ & 1 \\
\hline
\end{tabular}

As mentioned above, we took into account the needs of intermediary inspections and understand the impact of audience participation in martial arts films and television on the image perception of tourist destinations at different levels. Hence, the dependent variable tourist destination image perception and the independent variable audience participation were regarded as a whole. Continuous variables were discussed regardless of dimensions. According to the scores of the audience participation of the samples, the individuals were divided into three groups: high, middle, and low. Moreover, the number of samples in each group accounted for $33.3 \%$. Subsequently, a series of multiple linear regression models were established to perform statistical tests on the aforementioned hypotheses. The model results are shown in Table 3.

Table 3. The impact of movie audience involvement and cultural contact on the perception of tourist destination image.

\begin{tabular}{ccccc}
\hline Variables & Model 1 & Model 2 & Model 3 & Model 4 \\
\hline Audience & $0.590^{* * *}$ & $0.181^{* *}$ & & \\
participation & & & $0.479^{* * *}$ & $0.101^{* * *}$ \\
medium & & $0.792^{* * *}$ & $0.119^{* * *}$ \\
high & & & $0.628^{* * *}$ \\
Cultural contact & & $0.537^{* * *}$ & 0.043 & 0.000 \\
Gender & 0.031 & 0.000 & 0.009 & -0.007 \\
Age & 0.020 & -0.003 & -0.060 & -0.022 \\
Level of & -0.051 & -0.021 & Controlled & Controlled \\
education & Controlled & Controlled & Controlled & Controlled \\
City & Controlled & Controlled & 0.353 & 0.600 \\
Sample size & 0.476 & 0.609 & & \\
$\mathrm{R}^{2}$ & & & & \\
\hline Note: ${ }^{* *} p<0.011^{* * *} p<0.001$. The reference term of the audience participation variable in the model is "low".
\end{tabular}

4.1.1. The Impact of the Participation of the Film and Television Audience on Cultural Contact and the Image Perception of Tourist Destinations

To test the role of the participation of the martial arts films and television audience on the image perception of tourist destinations, Model 1 was constructed and used as the benchmark for subsequent modeling. Model 1 only examined the role of audience participation with no level difference on the image perception of tourist destinations. After controlling all control variables, a positive relationship was observed between audience participation with no level difference and the image perception of tourist destinations. Thus, Hypothesis 1 was supported. To gain a deeper understanding of the relationship between the two, Model 3 divided martial arts films and television audiences into groups for further testing. The results showed that Hypothesis 1 was still valid for the participation of martial arts films and television audiences at different levels. Specifically, the tourist destination perception of the moderate group was lower than that of the high group at 0.479 units, while those in the high group had 0.792 units. Both coefficients were statistically significant. Moreover, the coefficients rose with the increase in the participation of martial arts films and television audiences. To test the relationship between the variables further, a multilevel regression was performed on each variable. As shown in Table 4, the participation of 
martial arts films and television audiences had a significant positive impact on cultural contact. Thus, Hypothesis 2 was established, and Hypothesis 1 was also further verified.

Table 4. Regression Analysis of Main Effect.

\begin{tabular}{|c|c|c|c|c|c|c|c|c|}
\hline \multirow{2}{*}{$\begin{array}{l}\text { Dependent } \\
\text { Variable }\end{array}$} & \multirow{2}{*}{$\begin{array}{l}\text { Independent } \\
\text { Variable }\end{array}$} & \multirow{2}{*}{$\begin{array}{l}\text { Standardized } \\
\text { Factors }\end{array}$} & \multirow{2}{*}{$\begin{array}{l}\text { Standard } \\
\text { Error }\end{array}$} & \multirow[t]{2}{*}{ T Value } & \multirow[t]{2}{*}{$p$} & \multicolumn{2}{|c|}{$\begin{array}{c}\text { 95\% Confidence } \\
\text { Interval }\end{array}$} & \multirow[t]{2}{*}{ Hypothesis } \\
\hline & & & & & & Lower Limit & Upper Limit & \\
\hline \multirow[t]{2}{*}{$\begin{array}{l}\text { Cultural } \\
\text { contact }\end{array}$} & \multirow{2}{*}{$\begin{array}{c}\text { Audience } \\
\text { participation } \\
\mathrm{R}^{2}\end{array}$} & 0.780 & 0.035 & 22.602 & 0.000 & 0.713 & 0.849 & $\mathrm{H} 2$ \\
\hline & & 0.608 & \multicolumn{6}{|c|}{$\mathrm{F}=510.834, p<0.001$} \\
\hline \multirow{3}{*}{$\begin{array}{c}\text { Image } \\
\text { perception of } \\
\text { tourist } \\
\text { destinations }\end{array}$} & \multirow{3}{*}{$\begin{array}{c}\text { Audience } \\
\text { participation } \\
\text { Cultural } \\
\text { contact } \\
\mathrm{R}^{2}\end{array}$} & 0.203 & 0.048 & 3.698 & 0.000 & 0.083 & 0.271 & $\mathrm{H} 1$ \\
\hline & & 0.616 & 0.048 & 11.238 & 0.000 & 0.442 & 0.630 & H3 \\
\hline & & 0.615 & \multicolumn{6}{|c|}{$\mathrm{F}=261.399, p<0.001$} \\
\hline
\end{tabular}

\subsubsection{Intermediary Inspection of Cultural Contact}

Models 2 and 4 preliminarily tested the effect of cultural contact on the image perception of tourist destinations. Model 2 added the pre-dependent variable cultural contact on the basis of Model 1. The results showed that cultural contacts had a significant impact on the tourism destination image perception. For each additional $1 \mathrm{Ge}$ score, tourism destination image perception was raised by 0.537 units, taking into account the scale of the assigned score. The highest score was 5 points. Therefore, the increase was large. At the same time, the coefficient of audience participation in Model 2 was significantly lower than that in Model 1, a decrease of 0.409 units. However, it was still statistically significant. This outcome demonstrated that after joining the pre-dependent variable cultural contact, the positive effect of martial arts films and television audience participation on the image perception of tourist destinations still existed, but the effect is significantly reduced. Hypothesis 3 was supported. Model 4 was further verified. The coefficient for audience participation in martial arts television in the model appeared more pronounced compared with that in Model 2. The participation of moderate and high groups of martial arts and film and television audiences fell by 0.489 and 0.471 units, respectively. However, they were also statistically significant. Combining the results of Models 1 to 4 , the mediating role of cultural contact was initially verified.

According to the mediating effect analysis procedure, we referred to Hayes's Model 14 and bootstrap method to analyze the mediating effect further [46]. This method calculates the direct effect coefficient and the indirect effect coefficient of the intermediary through repeated re-sampling of the original sample. Moreover, it tests whether the coefficient of the intermediary effect is significant through the confidence interval. The test results of the present study are shown in Table 5 . The results showed that the sample size was selected at 5000 . Under the $95 \%$ confidence interval, the result of the mediation test did not contain 0 (lower limit 0.379 and upper limit 0.570 ), thus indicating that the mediating effect of cultural contact was significant. In addition, the value of the mediating effect was 0.480 . After controlling for the intermediary variable cultural contact, the influence of the pre-dependent variable, that is, audience participation in martial arts films and television, on the result variable tourism destination image perception was still significant. The interval (lower limit 0.083 and upper limit 0.271 ) did not contain 0 , and the effect value was 0.203 . Therefore, cultural contact plays a mediating role in the influence of film and television audience participation on the image perception of tourist destinations. Hence, the result provided support for Hypothesis 4 . To test the mediating effect of cultural contact between the three dimensions of martial arts films and television audience participation and the image perception of tourist destinations further, the three dimensions were tested separately. The results of this examination are shown in Table 5. The mediating effect of cultural contact between behavioral participation (lower limit 0.342, upper limit 0.492 ) and emotional participation (lower limit 0.420 , upper limit 0.578 ) on the image perception of 
tourist destinations was significant, and the mediating effect of the former $(0.421)$ was less than that of the latter (0.499). Moreover, behavioral participation (lower limit 0.111 and upper limit 0.266) and emotional participation (lower limit of 0.009, upper limit of 0.158) had a direct role in promoting the image perception of tourist destinations. Therefore, cultural contact had a direct effect on the image perception of tourist destinations in behavioral participation and emotional participation. Hence, a partial mediation effect existed. Cultural contact had a significant mediating effect on the image perception of tourist destinations in the referential mapping (lower limit 0.441 and upper limit 0.630), and the effect value was 0.532 . Meanwhile, the referential mapping (lower limit -0.030 and upper limit 0.111 ) had a significant effect on the image perception of tourist destinations. These outcomes revealed that no direct promotion existed. Hence, cultural contact played a completely intermediary role in the impact of reference mapping on the perception of tourist destinations.

Table 5. Regression Coefficients of the Mediation Model.

\begin{tabular}{ccccc}
\hline Variables & Types & $\begin{array}{c}\text { Standardized } \\
\text { Factor }\end{array}$ & $\begin{array}{c}\text { Bootstrap } \\
\text { Standard Error }\end{array}$ & $\begin{array}{c}\text { 95\% Confidence Interval } \\
\text { Upper Limit }\end{array}$ \\
\hline Behavioral & Direct effect & 0.217 & 0.040 & 0.111 \\
participation & Indirect effect & 0.421 & 0.039 & 0.342 \\
Emotional & Direct effect & 0.111 & 0.038 & 0.009 \\
participation & Indirect effect & 0.499 & 0.041 & 0.420 \\
Referential & Direct effect & 0.057 & 0.036 & -0.030 \\
mapping & Indirect effect & 0.532 & 0.048 & 0.158 \\
\hline
\end{tabular}

\subsection{Discussion}

The results of this research show that groups with higher participation in martial arts films and television also have a higher perception of the image of Foshan's tourist destination. This outcome fully shows that martial arts films indeed create a helpful image perception of the tourist destination and verifies that audience participation directly influences their perception of the image of tourist destinations Foshan [7]. Martial arts films will promote tourism in Foshan, which is an important means of spreading Foshan culture. Film and television works can deepen audience participation to achieve a better image perception effect of tourist destinations [39]. In addition, the research results show that behavioral participation and emotional participation are better than referential mapping, which is also consistent with previous research results [14]. According to the above content, film and television are not only able to achieve the purpose of promoting Foshan martial arts itself but are also able to shape the perception of the image of Foshan's tourist destination through audience participation. Therefore, in the context of Chinese tourism and the increasing acceptance and recognition of Chinese culture in the world, the hometowns of martial arts, the birthplaces of martial arts, and the inheritances of martial arts as an intangible cultural heritage should deeply explore the distinctive and distinguishable martial arts culture. Such exploration can be achieved by learning from Foshan's experience in film and television tourism, creating a positive tourist destination image for the audience through film and television communication, and attracting visitors to travel, which also meets the needs of the development of film and television industry [47]. At present, the value of martial arts is more embodied in the aspects of aesthetics, entertainment, and fitness. The commercialization and industrialization of martial arts still need further development. The best means to achieve films of socialization and commercialization is to combine tourism with film. Given their numerous common or similar characteristics Film and television tourism and cultural tourism can be combined to achieve true sustainable development [48]. For instance, "Shaolin Temple" has promoted the local tourism industry better by enhancing tourists' overall image perception of "Shaolin Temple" internationally and promoting the development of "Shaolin Temple" tourism [48]. Similarly, Foshan has also formulated corresponding market strategies for martial arts tourism [49] by focusing 
on introducing martial arts tourism content related to "ancient" and "vulgar" themes, such as "Huang Feihong" and "Ye Wen" as market selling points to stimulate tourism consumption demand of related groups [42].

Audience participation in martial arts films and television can increase the audience's cultural contact with Foshan. Meanwhile, cultural contact can enhance the image perception of Foshan's tourist destinations and play an important intermediary role in the process of audience participation in enhancing the perception of Foshan's tourist destinations. Through the in-depth participation of the audience in film and television works, cultural contact with Foshan martial arts has increased, which helps enhance the image perception of Foshan's tourist destination. This trend also shows that under the dual background of cultural tourism and film and television tourism, audiences usually manifest different motives and interests in experiencing and learning various cultures [50]. Contacting local culture and getting to know the local people are the main motivations for cultural tourism or film and television tourism [38]. At the same time, higher audience participation in the film entails a greater degree of cultural contact, thereby creating a more "perfect" tourist destination image. This "perfect" tourist image can often stimulate potential tourists' travel behavior intentions $[38,43]$. Martial arts films have been brought into the contact culture phenomenon, thus making it one of the most popular types of cultural popularity. These films have also given rise to a large group of martial arts fans. However, this group is the most loyal among potential tourists. Thus, relevant units and departments only need a little guidance to stimulate their tourism behavior thoroughly. Martial arts films and television may link the eastern and western cultures as well as the ancient and modern cultures of martial arts. Individuals would like to learn more about the birthplace of martial arts as they become more deeply immersed in martial arts culture [40]. For example, "Shaolin Temple" has enabled its audience to delve into both the culture of martial arts and the pleasant scenery of Mount Song [51]. The development of martial arts films and television has fully embodied the culture of martial arts from the beginning to the present. Moreover, culture will never be separated from the place. Only by going deep into the actual location can we have an in-depth understanding of the culture [52]. This perception is also at the core of martial arts films and television tourism [42]. Audiences come into contact with martial arts culture through martial arts films and television, and the intuitive sensory impact of this contact influences visitors who are nostalgic for local culture. Cultural landscapes that are linked to martial arts are more "vivid than traditional static ones, thereby enhancing the audience's perception of the image of the tourist destinations of martial arts films and television [53].

In summary, the participation of martial arts films and television audiences can enhance the image perception of tourist destinations. Additionally, cultural contact has an intermediary effect between the two. Therefore, drawing on the experience of Foshan martial arts films and television tourism, other martial arts hometowns, martial arts birthplaces, and countless places with intangible cultural heritage inheritance should give full play to the publicity role of film and television tourism when filming related film and television works [7]. Martial arts projects should pay attention to the integration of martial arts culture and the shaping of the local tourism image while shooting film and television works for publicity. At the same time, filmmakers should not blindly shoot their creations. Instead, their production should be aimed at promoting audience participation, as these film and television works can bring greater benefits to the locality. Moreover, the development of tourism resources related to martial arts is sustainable for the inheritance and protection of martial arts culture.

\section{Conclusions and Implications}

\subsection{Conclusions}

This study takes the image perception of tourist destinations as the dependent variable and the audience participation of martial arts films and television as the independent variable to explore the mechanism of audience participation in the image perception of 
tourist destinations in martial arts films and television tourism. It further explores the mediating effect of cultural contact. On the basis of the Audience Participation Scale, the Tourist Destination Image Perception Scale, and the Cultural Exposure Scale, the researchers of the current study surveyed 331 subjects who had never been to Foshan and watched Foshan-related martial arts films and television works. Then, a multi-layer regression model was established to test the rationality and validity of the theoretical model.

The results show the following: (1) A positive correlation exists between Wushu film and television audience participation and tourism destination image perception. This participation can enhance the image perception of tourism destinations; (2) A positive relationship exists between martial arts films and television audience participation and cultural contact. In addition, the participation of the audience can increase audience cultural contact; (3) A positive relationship exists between cultural contact and the image perception of tourist destinations. Moreover, cultural contact can enhance this perception; (4) Cultural contact has an intermediary effect between the participation of film and television audiences and the image perception of tourist destinations. An intermediary effect also exists in the three dimensions of behavior participation, emotional participation, and reference mapping of film and television audience participation.

\subsection{Implications}

Today, as the cultural industry has become a pillar industry of the national economy, film and television, as important cultural communication media, have made film and television tourism an important driving force for the development of cultural and tourism industries in various destinations. The scenery of these destinations promotes the creation of film and television dramas. The development of attractions driven by film and television drama is one of the models of the sustainable development of tourist destinations. Excellent film and television works can increase the popularity and reputation of tourist destinations. Through this recognition, tourist attractions can be given new vitality due to the influence of film and television works and attract tourists to return.

This research reveals that the audience participation can enhance the image perception of martial arts films and television tourism. It contributes to the sustainable development of tourism destinations. As a communication medium, film and television productions contain scenery and stories that stimulate viewers' curiosity. The audience expects to seek authenticity on the spot, which brings more tourists to the destination and promote the development of the local tourism industry. This prospect is the premise of innovative tourism projects and sustainable development. Besides, with the continuous innovation and development of technology in the information age, audience participation methods are also advancing. Various methods facilitate the in-formation dissemination of film and television works and also allow the destination culture in the film and television works to spread farther and bring more economic benefits to the tourist destinations. Therefore, the destination actively attracts film and television crews to shoot in a variety of ways, guides active audience participation, and produces excellent film and television works to stimulate tourists to visit and promote the destination's tourism industry and its sustainable development.

As an important basis for the survival of tourist destinations, culture is essential to the sustainable development of destinations. The research also mentions cultural contact as an important intermediary role. Cultural contact is an important part of the experience of tourists. Before this contact, the local customs and culture are transmitted through film and television works. Then, the tourists' sense of cultural acquisition in the tourism experience project will be one of the ways through which the cultural resources of tourist destinations can develop continuously. Furthermore, the common drive of culture and creativity will be an important support for the sustainable development of tourist destinations. The props in film and television dramas are innovatively developed into tourist souvenirs, and film and television derivatives are developed to enrich tourism products. These supplements increase the income of the local tourism industry and promote the development of the local economy. Therefore, the use of film and television works to spread the destination image, 
improve the quality of tourists' cultural experience and interaction, and optimize cultural tourism products are important channels for the sustainable development of tourism destinations based on culture. Integrating tourism and sightseeing with film and television shooting, cultural dissemination, and leisure and entertainment is an important reason as well as a crucial method for the viable and healthy development of tourist destinations.

With the intensification of competition in the tourism industry, an attractive tourism image has become a substantial part of the development strategy of tourism destinations. The image of tourist destinations not only relies on local cultural resources and characteristics but also requires a certain degree of image publicity and marketing. Culture is updated in the continuous spread through film and television works, so that the image of tourism destinations can continue to develop and form a sustainable link. Therefore, both the development of tourist destinations and the power of media communication require cultural identity and cultural contact. On this basis, film and television tourism can promote the sustainable development of tourist destinations.

\subsection{Limitations and Future Research}

This research fills the gaps in the study of martial arts and film and television tourism and confirms the relationship among the variables of film and television tourism. This relationship has been proven to play a vital role in the development of such tourism. However, this study still has some limitations. First, the main object of this study is the Wushu film and television works in Foshan. No comparison of different film and television works has been made. Hence, the conclusions of this work need to be further tested. In addition, the article only discusses the impact of audience participation and lacks the investigation of other variables, such as tourism experience and tourist behavior intentions. Therefore, the conclusions must be deepened. Second, the common problems related to the measurement error of the outcome variable and the antecedent variable in the linear model also constitute a limitation of the study. Finally, the participants in this study are Chinese tourists. The researchers have not fully considered the impact of the cultural identity of different countries on the consumption intentions of local and foreign tourists. Future research should pay more attention to the cross-cultural analysis of tourists and the in-depth exploration of the relationship of variables in a cross-cultural environment.

Author Contributions: Conceptualization, Y.Z. and H.C.; methodology, Y.Z.; validation, Y.Z.; investigation, Y.Z.; writing-original draft, Y.Z. and H.C.; writing-review and editing, H.C., Y.Z., R.L., and M.Z. All authors have read and agreed to the published version of the manuscript.

Funding: This work was supported by the Ministry of Culture and Tourism of the People's Republic of China (Grant number WLRCY2019-012) and the Postgraduate Innovation Development Fund Project of Shenzhen University (Grant number 315-0000470419).

Conflicts of Interest: The authors declare no conflict of interest.

\section{References}

1. Pawelec, P.; Swider, P.; Cynarski, W.J. Martial Arts Tourism: Meta-Analysis of Publications from 2005-2020. Sustainability 2020, 12, 7069. [CrossRef]

2. Figueiredo, A.; Błach, W.; Bujak, Z.; Maroteaux, R.; Cynarski, W. Martial Arts Tourism of the "Europe-Far East" Direction, in the Opinion of Grand Masters. Sustainability 2020, 12, 8857. [CrossRef]

3. Hudson, S.; Ritchie, J.R.B. Film tourism and destination marketing: The case of CaptainCorelli's Mandolin. J. Vacat. Mark. 2006, 12, 256-268. [CrossRef]

4. Wen, H.; Josiam, B.M.; Spears, D.L.; Yang, Y. Influence of movies and television on Chinese Tourists perception toward international tourism destinations. Tour. Manag. Perspect. 2018, 28, 211-219. [CrossRef]

5. Jang, Y.; Dan, Y.; Lee, H. A Study on the Revitalization Strategies of Chinese Film-induced Tourism. J. Cult. Ind. Stud. 2019, 19, 49-56.

6. Rittichainuwat, B.; Rattanaphinanchai, S. Applying a mixed method of quantitative and qualitative design in explaining the travel motivation of film tourists in visiting a film-shooting destination. Tour. Manag. 2015, 46, 136-147. [CrossRef]

7. Kim, S. Audience involvement and film tourism experiences: Emotional places, emotional experiences. Tour. Manag. 2012, 33, 387-396. [CrossRef] 
8. Lai, K.; Li, X. Tourism Destination Image: Conceptual Problems and Definitional Solutions. J. Travel Res. 2016, 55, 1065-1080. [CrossRef]

9. Tomaz, K.; Walanchalee, W. One does not simply... project a destination image within a participatory culture. J. Destin. Mark. Manag. 2020, 18, 100494.

10. Michael, N.; Balasubramanian, S.; Michael, I.; Anestis, K.F. Underlying motivating factors for movie-induced tourism among Emiratis and Indian expatriates in the United Arab Emirates. Tour. Hosp. Res. 2020, 20, 435-449. [CrossRef]

11. Marafa, L.M.; Chan, C.S.; Li, K. Market Potential and Obstacles for Film-Induced Tourism Development in Yunnan Province in China. J. China Tour. Res. 2020, 1-23. [CrossRef]

12. Dubois, L.E.; Griffin, T.; Gibbs, C.; Daniel, G. The impact of video games on destination image. Curr. Issues Tour. 2021, 24, 554-566. [CrossRef]

13. Hao, X.; Xu, S.; Zhang, X. Barrage participation and feedback in travel reality shows: The effects of media on destination image among Generation Y. J. Destin. Mark. Manag. 2019, 12, 27-36. [CrossRef]

14. Fu, H.; Ye, B.H.; Xiang, J.Z.; Reality, T. V Audience travel intentions, and destination image. Tour. Manag. 2016, 55, 37-48. [CrossRef]

15. Soratana, K.; Landis, A.; Jing, F.; Suto, H. Sustainable Development of Tourism. In Supply Chain Management of Tourism Towards Sustainability; Springer: Cham, Switzerland, 2021.

16. Ruhanen, L.; Moyle, C.; Moyle, B.D. New directions in sustainable tourism research. Tour. Rev. 2019, 74, 138-149. [CrossRef]

17. Lu, Z. Politics and Identity in Chinese Martial Arts; Taylor and Francis: Abingdon, UK, 2018.

18. Han, Z. Research on the Inheritance and Innovative Development of Chinese Martial Arts Culture under the Background of Cultural Confidence. In Proceedings of the 2019 International Conference on Social Science and Education (ICSSAE 2019), Xiamen, China, 23-25 August 2019.

19. Jiang, Y.; Di Hu, H.; Hu, J. Based on Goal Programming Method of Traditional Chinese Martial Arts Culture Protection and Inheritance. J. Comput. Theor. Nanosci. 2016, 13, 10025-10029. [CrossRef]

20. Yu, S.; Zong, W. The present situation of Chinese martial arts heritage means and development. In Proceedings of the 16th Asian Games Science Congress Organizing Committee, Guangzhou, China, 10-12 October 2010; Volume 2, pp. 249-250.

21. Zhang, J. A Cultural Discourse Analysis to Chinese Martial Arts Movie in the Context of Glocalization: Taking Crouching Tiger, Hidden Dragon and Hero as Cases. Adv. Lang. Lit. Stud. 2019, 10, 32-41. [CrossRef]

22. Yajun, Q. Evolution and Prospect of Chinese Martial Arts during the Rising Course of China. In Proceedings of the 2016 2nd International Conference on Economics, Management Engineering and Education Technology, Sanya, China, 12-13 November 2016; Volume 3, pp. 1121-1123.

23. Sood, S.; Rogers, E.M. Dimensions of parasocial interaction by letter-writers to a popular entertainment-education soap opera in India. J. Broadcast. Electron. Med. 2000, 44, 386-414. [CrossRef]

24. Tasci, A.D.A.; Gartner, W.C.; Cavusgil, S.T. Conceptualization and Operationalization of Destination Image. J. Hosp. Tour. Res. 2007, 31, 194-223. [CrossRef]

25. Yoo, E.; Buzinde, C.N. Gazing upon the kingdom. An Audience Reception Analysis of a Televised Travelogue. Ann. Tour. Res. 2012, 39, 221-242. [CrossRef]

26. Baloglu, S.; Mccleary, K.W. A model of destination image formation. Ann. Tour. Res. 1999, 26, 868-897. [CrossRef]

27. Cronje, D.F.; Du Plessis, E. A review on tourism destination competitiveness. J. Hosp. Tour. Manag. 2020, 45, 256-265. [CrossRef]

28. Noelia, A.V.; Antonio, F.B.J.; Pablo, D.C. Film tourism in Spain: Destination awareness and visit motivation as determinants to visit places seen in TV series. Eur. Res. Manag. Bus. Econ. 2021, 27, 100135.

29. Li, Y.Q.; Liu, C.H. Impact of cultural contact on satisfaction and attachment: Mediating roles of creative experiences and cultural memories. J. Hosp. Mark. Manag. 2020, 29, 221-245. [CrossRef]

30. Iber, J.; Santa, F.E. Hispanic culture: Preserving identity in a tourist town. J. West 2005, 44, 107.

31. Buchmann, A.; Moore, K.; Fisher, D. Experiencing film tourism Authenticity \& Fellowship. Ann. Tour. Res. 2010, 37, $229-248$.

32. Frost, W. Braveheart-ed, Ned, Kelly: Historic films, heritage tourism and destination image. Tour. Manag. 2006, 27, 247-254. [CrossRef]

33. Su, H.J.; Huang, Y.-A.; Glen, H.; Brodowsky, G.; Kim, H.J. The impact of product placement on TV-induced tourism: Korean TV dramas and Taiwanese viewers. Tour. Manag. 2011, 32, 805-814. [CrossRef]

34. Pyo, S.; Chang, H.S. Relating Expectation, Perception and Image Formation Process on Intention to Revisits. 2000, pp. 479-487. Available online: http:/ / apps.webofknowledge.com/full_record.do?product=UA\&search_mode=GeneralSearch\&qid=1\&SID= 5ATPgfvUShWsRaKf9or\&page=1\&doc=2 (accessed on 31 March 2021).

35. Prayag, G. Tourists' evaluations of destination image, satisfaction, and future behavioral intentions-the case of mauritius. J. Travel Tour. Mark. 2009, 26, 836-853. [CrossRef]

36. Talhah, H.F.; Hashim, R. Homestay destination: Assessing destination's food image, tourists' satisfaction and tourists' revisit intention. In Proceedings of the Current Issues in Hospitality and Tourism Research and Innovations-Proceedings of the International Hospitality and Tourism Conference, Kuala Lumpur, Malaysia, 3-5 September 2012; pp. 371-375.

37. Williams-Burnett, N.J.; Fallon, J. What really happens in Kavos. J. Place Manag. Dev. 2017, 10, 183-195. [CrossRef]

38. Chen, H.; Rahman, I. Cultural tourism: An analysis of engagement, cultural contact, memorable tourism experience and destination loyalty. Tour. Manag. Perspect. 2018, 26, 153-163. [CrossRef]

39. Li, J.F. Artistic Characteristics of Foshan Fancy Lantern. In Proceedings of the 4th International Conference on Arts, Design and Contemporary Education (ICADCE 2018), Zhengzhou, China, 6-8 May 2018; pp. 141-143. 
40. Gao, J.; Lin, S.T.; Zhang, C.Z. Authenticity, involvement, and nostalgia: Understanding visitor satisfaction with an adaptive reuse heritage site in urban China. J. Destin. Mark. Manag. 2020, 15, 10. [CrossRef]

41. Li, X.D.; Li, P. An empirical study on the purchase of sports public service by local government in China-Case of Jing'an district in Shanghai, Changsha and Foshan. In Proceedings of the 2013 International Conference on Advances in Social Science, Humanities, and Management (ASSHM-13), Guangzhou, China, 14-15 December 2013; pp. 738-743.

42. Ouyang, Z.; Gursoy, D.; Sharma, B. Role of trust, emotions and event attachment on residents' attitudes toward tourism. Tour. Manag. 2017, 63, 426-438. [CrossRef]

43. Brislin, R.W. Back-Translation for Cross-Cultural Research. J. Cross Cult. Psychol. 1970, 1, 185-216. [CrossRef]

44. Sood, S. Audience involvement and entertainment-education. Commun. Theory 2002, 12, 153-172.

45. Gnoth, J.; Zins, A.H. Developing a tourism cultural contact scale. J. Bus. Res. 2013, 66, 738-744. [CrossRef]

46. Hayes, A.F. PROCESS: A Versatile Computational Tool for Observed Variable Mediation, Moderation, and Conditional Process Modeling1. 2012. Available online: https:/ / www.semanticscholar.org/paper/PROCESS-\%3A-A-Versatile-Computational-Toolfor-\%2C-\%2C-1-Hayes/862dd61cccad6b39ffe890557db19a6356bbe8ca (accessed on 31 March 2021).

47. Lingling, W.; Zhang, G. Problems and reflection of Martial Arts industrialization. J. Shandong Inst. Phys. Educ. Sports 2013, $29,40-45$.

48. Zhiqiang, W.; Wei, Q. Study of Integrated Development of Chinese Wushu and Tourism. J. Shanghai Phys. Educ. Inst. 2003, $1,28-31$.

49. Hua, P. Classified Research on Tourism Market and Its Significance-A Case Study of Foshan City. Tour. Trib. 2002, 3, 49-54.

50. Barza, S.; Memari, M. Movie Genre Preference and Culture. Procedia Soc. Behav. Sci. 2014, 98, 363-368. [CrossRef]

51. Xiaotao, Y.; Kam, H.; Wei, H.; Yung, T. Tourism representation by DMOs at religious sites: A case of Shaolin Temple, China. Tour. Manag. 2019, 75, 569-581.

52. Connell, J. Film tourism—Evolution, progress and prospects. Tour. Manag. 2012, 33, 1007-1029. [CrossRef]

53. Teng, H.-Y.; Chen, C.-Y. Enhancing celebrity fan-destination relationship in film-induced tourism: The effect of authenticity. Tour. Manag. Perspect. 2020, 33, 100605. [CrossRef] 